\title{
1 Thermal Performance of a Polymer Composite Webbed-Tube Heat Exchanger
}

Juan Cevallos, Avram Bar-Cohen, and David C. Deisenroth

University of Maryland, Department of Mechanical Engineering, College Park, MD, 20740

Keywords: Heat exchangers, Polymer composites, Polymer heat exchangers, Thermal anisotropy, Thermal conductivity

\section{ABSTRACT}

This paper presents an in-depth study of the thermal performance of a gas-to-liquid "webbed tube" polymer heat exchanger. The heat exchanger was fabricated from a thermally enhanced polymer composite, consisting of a Nylon 12 matrix filled with carbon fibers. A laboratory-scale prototype heat exchanger was built using injection molding and tested on a cross-flow air-to-water heat exchange apparatus. The thermal performance of this laboratory webbed-tube polymer composite heat exchanger is studied in depth through an extended set of experiments, application of existing empirical correlations, and detailed computational fluid dynamic (CFD) simulations. The laboratory webbed-tube heat exchanger prototype provided a maximum UA value of $1.8 \mathrm{~W} / \mathrm{K}$ and a volume-specific heat transfer coefficient of $14 \mathrm{~kW} / \mathrm{m}^{3} \mathrm{~K}$. The experimental results, in conjunction with numerical simulations, were used to determine an "effective" thermal conductivity of $1.8 \mathrm{~W} / \mathrm{m} \cdot \mathrm{K}$ for the injection-molded nyloncarbon composite material in the webbed-tube heat exchanger configuration.

\section{Introduction}

Polymer heat exchangers (PHXs) have received considerable attention since their invention more than 40 years ago due to their corrosion resistance, low weight, and low manufacturing cost. New polymer composites with higher strengths, thermal conductivities, and thermal stability promise to bridge the performance gap between polymers and corrosion resistant metals. This paper introduces a novel "webbed-tube" heat exchanger (WTHX) configuration and provides the first-reported empirical data for a laboratory prototype, polymer composite heat exchanger. This polymer heat exchanger design offers reduced mass, compared to more classical designs, while taking advantage of the process-induced anisotropy to yield favorable heat transfer characteristics. A numerical exploration of the processinduced anisotropy of carbon fiber reinforced polymer composite is used to set the expected bounds on the wall thermal conductivity. The thermal performance of this laboratory "webbed-tube" polymer composite heat exchanger is studied in depth through an extended set of experiments, application of existing empirical correlations, and detailed computational fluid dynamic (CFD) simulations.

Polymer heat exchangers (PHXs) were introduced first by DuPont in 1965 [1]. These heat exchangers consisted of bundles of many flexible, thin, small-diameter polytetrafluoroethylene (PTFE) tubes that were joined at their ends to form a honeycomb structure that could be used in shell-and-tube and 
immersion heat exchanger configurations. These early designs were adopted for specific industrial applications, such as pickling in steel manufacturing, heating of agitated reactor vessels and heating/cooling of distilled water. The wide availability and versatility of polymers has since driven the interest of the research community toward the use of these materials in a broad range of heat exchanger applications [2-4].

When corrosive fluids are present in the heat exchange process, polymers are an increasingly popular material choice as an alternative to exotic metals and graphite [5], especially when strong acidic solutions are present [6]. In addition, due to their low surface energy and smooth surface, fouling deposits have a lower propensity to adhere to polymers, which reduces the fouling thermal resistance. In seawater heat exchangers, fouling is generally a costly problem due to the many modes of fouling that occur in seawater: corrosion, biological, crystallization and particulate [7]. Therefore, the material properties of polymers make them good candidates to replace costly exotic metals, such as coppernickel alloys and titanium in this important future application.

Several reviews of the latest advancements in PHX technology have been published. Zaheed and Jachuck [8] reviewed the use of polymers in compact heat exchangers, paying special attention to designs made of high temperature polyetheretherketone (PEEK) with 100- $\mu \mathrm{m}$-films fabricated with corrugations to enhance boundary layer mixing. A review by T'Joen et al. [9], aimed to assess the merits of PHXs for heating, ventilation, air-conditioning and refrigeration applications. Notable heat exchanger applications are reviewed in detail, and special attention is paid to polymer matrix composites, which can offer vast improvements in thermal conductivity. Most notably, fiber-filled composites show the most promising results because of their availability as injection molding resins. Composites with thermal conductivities up to two orders of magnitude higher than unreinforced polymers have been made possible by the use of pitch-based carbon fibers, which offer fiber thermal conductivities of approximately $800 \mathrm{~W} / \mathrm{m} \cdot \mathrm{K}$, which are intermediate to PAN-based fibers at approximately $160 \mathrm{~W} / \mathrm{m} \cdot \mathrm{K}$ and CVD fibers at 1950 $\mathrm{W} / \mathrm{m} \cdot \mathrm{K}$. Effective utilization of carbon nanotubes, with reported conductivities of $2000-6600 \mathrm{~W} / \mathrm{m} \cdot \mathrm{K}$, could further enhance the thermal properties of polymer composites [10]. It is noteworthy that with improved fiber conductivity, polymer composites approach the thermal properties of common corrosion resistant metals (e.g. titanium and stainless steel) and thus, can be considered as replacements for metals in applications where seawater is used as a direct coolant for industrial processes.

\section{Webbed-Tube Heat Exchanger}

A webbed-tube heat exchanger consists of a stack of thin rectangular plates that are separated from each other in the thickness direction to allow one of the fluids (Fluid 1) to flow between the plates. Embedded in the plates is an array of tubular channels that can span the length of the plate. This tubular array serves as the passage for the second fluid (Fluid 2). In practice, the diameter of the tubes can be substantially larger than the thickness of the plate itself, effectively creating a "bumpy" plate or webbed-tube array, as shown in Figure 1. The effects of these bumps on the flow field and thermal

72 transport will be discussed in later sections of this paper. 


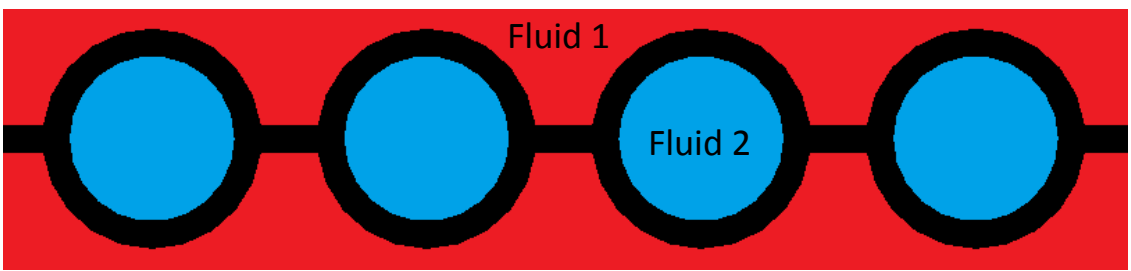

Figure 1 Profile view of webbed-tube heat exchanger plate

When Fluid 1 and Fluid 2 flow parallel to each other, the heat exchanger can operate in the co-current (same direction) or countercurrent (opposite direction) mode. When the flows are perpendicular, the heat exchanger is in a cross-flow configuration. Contiguous tube plates can be fully aligned or displaced in the lateral direction, relative to each other, to create staggered arrays of tubes (see Figure 2).

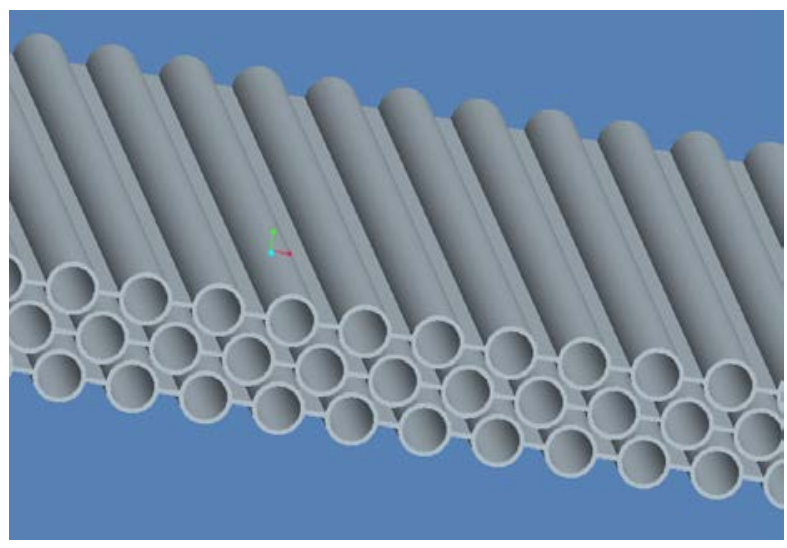

Figure 2 3D rendition of the WTHX geometry

\section{Thermo-Fluid Performance Comparison of a WTHX to a Plate-Fin Heat}

\section{Exchanger}

In order to illustrate the value of the WTHX design, its heat transfer performance was benchmarked against the more classical plate-fin design. For the example discussed here, which is based on heat exchange needs of a particular stage in a natural gas liquefaction process, both heat exchangers were assumed to be fabricated of a polymer composite and utilize a counter-flow configuration, with hot methane gas at $90^{\circ} \mathrm{C}$ and $500 \mathrm{kPa}$ being cooled by seawater at $35^{\circ} \mathrm{C}$ and $400 \mathrm{kPa}$ [29]. The volumetric flow rates of the two fluids were approximately equal, with the seawater flow rate kept constant at 0.02 $\mathrm{m}^{3} / \mathrm{s}$, and the gas flow rate varying from 0.02 to $0.1 \mathrm{~m}^{3} / \mathrm{s}$. Cross-sectional views of both $H X$ designs are shown in Figure 3. The plate-fin heat exchanger design was derived from configurations investigated in previous work and optimized for material and manufacturing cost [12] as well as total coefficient of performance [13]. The dimensions of the WTHX were then chosen such that methane and water velocities, within their respective channels, were comparable to those in the plate-fin design. 


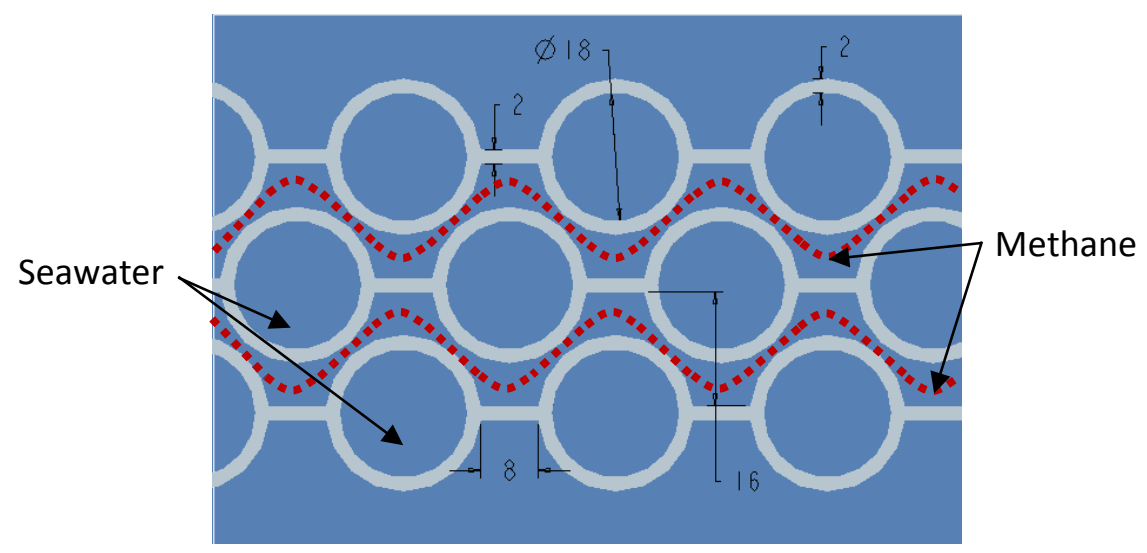

(a)

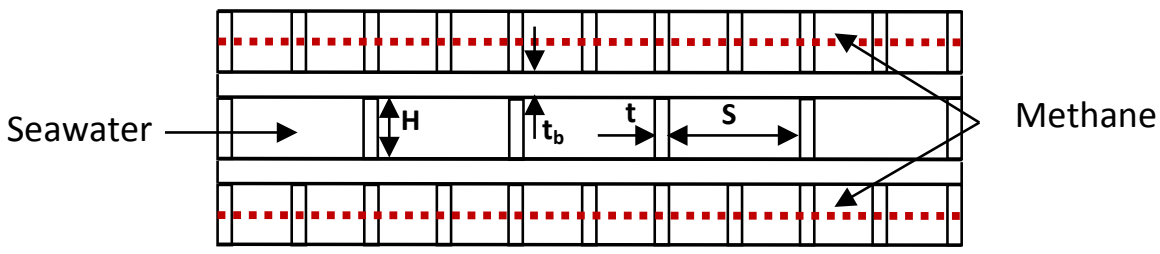

(b)

Figure 3 Sketches of heat exchangers used in performance comparison (a) Webbed-tube heat exchanger module (all dimensions in $\mathrm{mm}$, overall plate length and width $=1 \mathrm{~m}$ ). (b) Plate-fin heat exchanger module $\left(H=10 \mathrm{~mm}, S=3 \mathrm{~mm}, t=t_{b}=2 \mathrm{~mm}\right.$, plate length and width $=1 \mathrm{~m}$ ).

94 It is to be noted that, for the WTHX heat exchanger, the methane gas flows between the tube plates while the seawater flows inside the tubes. The control volumes used to calculate the heat transfer rate and pumping power are outlined with red dashed lines in the Figure 3. These constitute building blocks for a larger heat exchanger. In both cases, the control volume consists of a single set of seawater channels, which receives heat from the methane "half channels" above and below, so that the methane channels also transfer heat to the water channels on the opposite side.

Since the heat exchangers were designed to be constructed from fiber-filled polymer, the wall thermal conductivity was modeled with thermal conductivity anisotropy [14]. For purposes of this preliminary investigation, we assumed that the fibers mostly lie parallel to the plane of the wall, resulting in an inplane conductivity of $10 \mathrm{~W} / \mathrm{m} \cdot \mathrm{K}$ and through-plane conductivity of $0.65 \mathrm{~W} / \mathrm{m} \cdot \mathrm{K}$. For the plate-fin design, the described anisotropy results in the rectangular fins having an axial conductivity of $10 \mathrm{~W} / \mathrm{m} \cdot \mathrm{K}$, while the plate itself will have a conductivity of $0.65 \mathrm{~W} / \mathrm{m} \cdot \mathrm{K}$ for conduction in the through-thickness direction, as shown in Figure 3 (b). For the webbed-tube design, radial conduction through the tube is assumed, and since this direction is perpendicular to the planes of the wall (or the axial direction), the conductivity is taken as $0.65 \mathrm{~W} / \mathrm{m} \cdot \mathrm{K}$. Since the plate-separating two adjacent tubes-is exposed to methane on both sides, there is no significant conduction in the through-thickness direction in the plate. However, heat can be expected to conduct from the tubes into the plate and then convect into the methane, requiring that the plate be treated as an extended surface-anchored at the tube wall-with an axial 
112 conductivity of $10 \mathrm{~W} / \mathrm{m} \cdot \mathrm{K}$. With these parameters, the performance of the polymer composite heat 113 exchangers were determined, following the method described in [12], which models conduction

114 analytically while incorporating available convection correlations. The correlations used are detailed in

115 Appendix A.

116 Table 1 compares important geometrical and performance parameters of the WTHX and plate-fin heat 117 exchanger, under the assumed operating conditions. Fluid velocities, hydraulic diameters, pressure 118 drops, Reynolds numbers, and heat transfer coefficients were found to be very similar for the two heat 119 exchanger designs. As a consequence of these similarities, the pumping power, as a function of gas flow 120 rate, for both exchangers are very similar, as shown in Figure 4. It may also be observed from Figure 4 121 that the pumping power curves ("total" pumping power includes pumping power for seawater, while 122 the "gas only" pumping power is methane only) almost completely overlap. However, due to their 123 distinct geometries, the wetted areas on the seawater and methane sides are dissimilar, with the plate124 fin exchanger providing 1.55 more gas-side wetted area and the webbed-tube design providing 1.38 125 more water-side wetted area than the competing design.

126 Table 1 Heat exchanger parameters (Seawater inlet conditions: $0.02 \mathrm{~m}^{3} / \mathrm{s}, 35^{\circ} \mathrm{C}, 400 \mathrm{kPa}$. Methane inlet conditions: 0.02 to $1270.1 \mathrm{~m}^{3} / \mathrm{s}, 90^{\circ} \mathrm{C}, 500 \mathrm{kPa}$. Both exchangers have a counter-flow arrangement)

\begin{tabular}{cccc} 
& & Webbed-Tube & Plate-fin \\
Methane-side area & $\mathbf{m}^{\mathbf{2}}$ & 2.76 & 4.298 \\
\hline Water-side area & $\mathbf{m}^{\mathbf{2}}$ & 2.02 & 1.446 \\
\hline Methane hydraulic diameter & $\mathbf{m m}$ & 8.684 & 6.667 \\
\hline Water hydraulic diameter & $\mathbf{m m}$ & 18 & 16 \\
\hline Methane velocity & $\mathbf{m} / \mathbf{s}$ & $3.3-16.7$ & $2.8-14$ \\
\hline Water velocity & $\mathbf{m} / \mathbf{s}$ & 2.2 & 2.1 \\
\hline Methane pressure drop & $\mathbf{P a}$ & $76-1300$ & $77-1290$ \\
\hline Water pressure drop & $\mathbf{P a}$ & 4115 & 4200 \\
\hline Methane Reynolds number & - & $6700-34000$ & $4300-21800$ \\
\hline Water Reynolds number & - & 54700 & 46500 \\
\hline Gas heat transfer coefficient & $\mathbf{W} / \mathbf{m}^{2} \mathbf{K}$ & $104-370$ & $90-340$ \\
\hline Water heat transfer coefficient & $\mathbf{W} / \mathbf{m}^{2} \mathbf{K}$ & 11000 & 10700 \\
\hline Heat Exchanger Mass & $\mathbf{k g}$ & 7.9 & 11.9
\end{tabular}


129

130

131

132

133

134

135

136

137

138

139

140

141

142

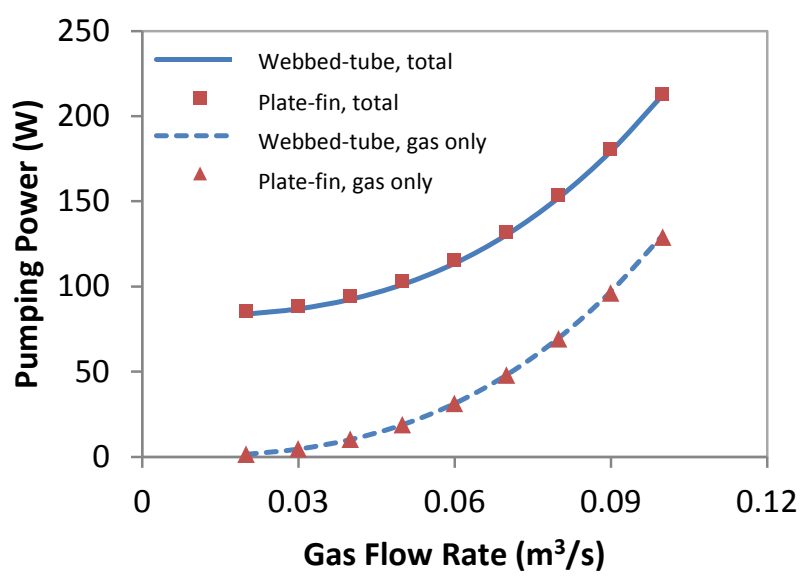

Figure 4 Heat exchanger pumping power (Seawater inlet conditions: $0.02 \mathrm{~m}^{3} / \mathrm{s}, 35^{\circ} \mathrm{C}, 400 \mathrm{kPa}$. Methane inlet conditions: $90^{\circ} \mathrm{C}, 500 \mathrm{kPa}$. Both exchangers have a counter-flow arrangement.

Figure 5 displays the dependence of the heat transfer rate on the gas flow rate for the conditions stated and reveals that the heat transfer rate of both heat exchangers is almost equal, despite significant geometric differences between these two designs. This is a somewhat surprising result, since due to the relatively low heat transfer coefficient in the gas channels, it is the gas side which controls the overall heat transfer rate in these heat exchangers. However, most of the area advantage of the plate-fin comes from the "extended" fin area whose heat transfer contribution must be corrected for the reduced surface temperature and lower fin efficiency. On the other hand, most of the gas-side wetted area of the webbed-tube heat exchanger is the external area of the tubes, or "bumps" on the plate, which does not suffer the reduced performance impact of fin efficiency. In this fashion, the WTHX can provide the same heat transfer rate as the plate-fin with the same pumping power, but much less surface area and, therefore, less mass.

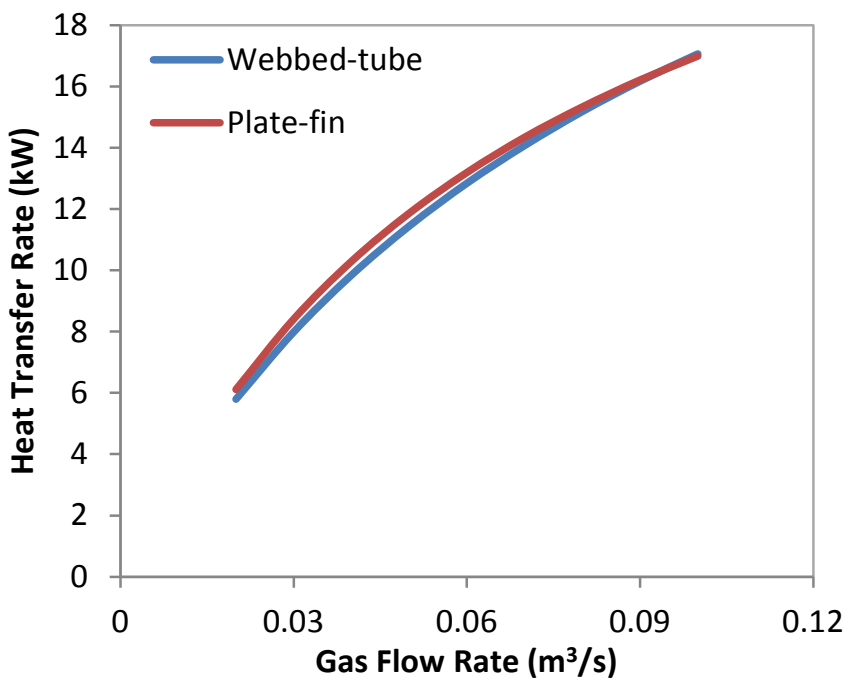


As a result of this near-equality in heat transfer rate but lower mass, the webbed-tube heat exchanger can provide more heat transfer per unit mass than the plate-fin. Figure 6 shows that the webbed-tube heat exchanger can transfer up to $50 \%$ more heat per unit of mass than the plate-fin heat exchanger, providing an opportunity for significant cost and weight reductions relative to the conventional plate-fin design.

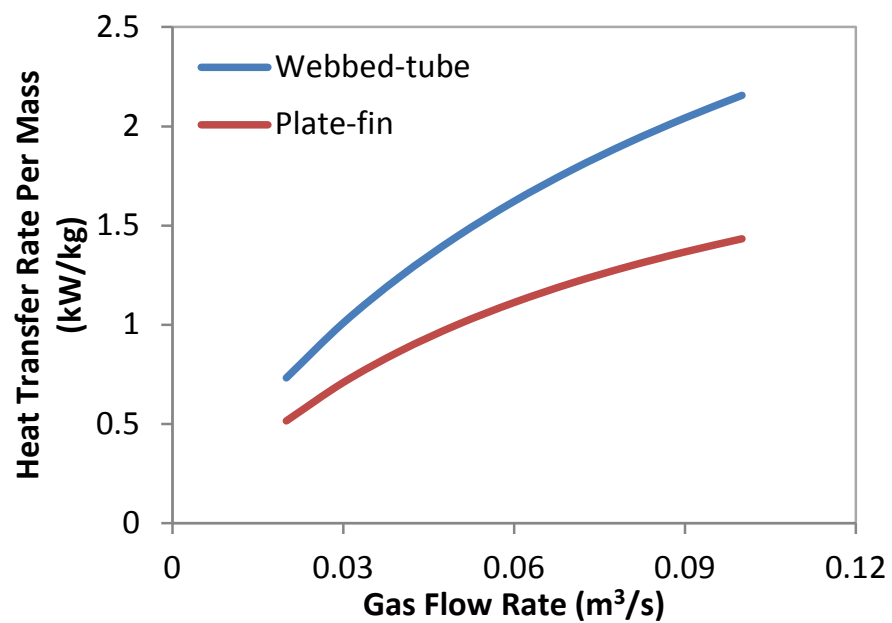

Figure 6 Heat exchanger mass-specific heat transfer rate (Seawater inlet conditions: $0.02 \mathrm{~m} / \mathrm{s}, 35^{\circ} \mathrm{C}, 400 \mathrm{kPa}$. Methane inlet conditions: $90^{\circ} \mathrm{C}, 500 \mathrm{kPa}$. Both exchangers have a counter-flow arrangement)

\section{WTHX Prototype}

To test the feasibility of using a polymer composite in a WTHX configuration and to provide a preliminary verification of the anticipated performance advantages, a prototype webbed-tube heat exchanger was built and tested on an air-to-water heat exchange apparatus at the University of Maryland's Department of Mechanical Engineering. A 4-layer array of webbed-tubes, constituting a single "building block" for a larger WTHX, served as the laboratory prototype. The experiments here were meant to confirm the feasibility of injection molding a polymer composite WTHX and to evaluate the thermal performance of a specific geometry that was readily manufacturable at local facilities.

The WTHX arrays were made by injection molding PolyOne NJ-6000 TC in a laboratory-scale injection molding "Baby-Plast" unit. The commercially available composite contains a pitch-derived carbon fiber filler with a thermal conductivity of $590 \mathrm{~W} / \mathrm{m} \cdot \mathrm{K}$, a density of $2.1 \mathrm{~g} / \mathrm{cm}^{3}$, fiber diameter of $10 \mu \mathrm{m}$, and an average fiber aspect ratio of 20 [15]. The polymer matrix of the composite is Nylon 12, which has a thermal conductivity of $0.25 \mathrm{~W} / \mathrm{m} \cdot \mathrm{K}$ and density of $1.14 \mathrm{~g} / \mathrm{cm}^{3}$ [16]. Based on the manufacturer's specification, the fiber weight percentage was $51.8 \%$ and the fiber volume fraction 0.33 [17]. The manufacturer further specifies the in-plane (along fiber axis) thermal conductivity to be in the range of 10-12 W/m.K [17], which was measured with the standard test method detailed in ASTM C177 [18]. Using the Nielsen model [19], the lower and upper bounds of thermal conductivity for this composite, corresponding to the transverse and aligned directions, respectively, can be determined to equal $k_{\perp}=$ $0.75 \mathrm{~W} / \mathrm{m} \cdot \mathrm{K}$ in the transverse direction and $k_{\|}=9.7 \mathrm{~W} / \mathrm{m} \cdot \mathrm{K}$ in the direction aligned with the orientation of the fibers. Note that the predictions from Nielsen's model strongly depend on the assumed maximum 
174 packing fraction ( 0.52 for the preceding calculations) [19] but do support the measured axial thermal

175 conductivity value.

176 It is, however, important to note, that in an injection molded structure, the final fiber orientation is

177 strongly dependent on the melt flow pattern, which tends to align fibers with the streamlines of the

178 flow. Thus the heat flow direction in the molded structure, dictated by the imposed temperature field,

179 may not be aligned with the fiber direction. Therefore, the observed thermal conductivity in an injection

180 molded component may not match the thermal conductivity values reported by manufacturers of fiber

181 filled polymer blends.

182 The dimensions of the molds were designed to fit a small injection machine, Baby-Plast, which is 183 available at the Advanced Manufacturing Laboratory at the University of Maryland [20]. Using Autodesk 184 Moldflow to simulate the injection molding process [14, 21], and considering the maximum shot size $185(6.5 \mathrm{cc})$ and injection pressure $(183 \mathrm{MPa})$ of the injection machine, appropriate wall thickness, size and 186 number of tubes, and tube length were chosen [22]. The resulting mold design is shown in Figure 7. The 187 mold was made from CNC milled aluminum. Note that the overall dimensions are limited by the length 188 of the fill tubes, the size of the mold piece itself, and the real estate available once the through holes for 189 holding screws are drilled. Additionally, the WTHX walls must be sufficiently thick that the resistance to 190 the flow of the melt does not result in voids and gaps, i.e. incomplete filling, in the molded features. 

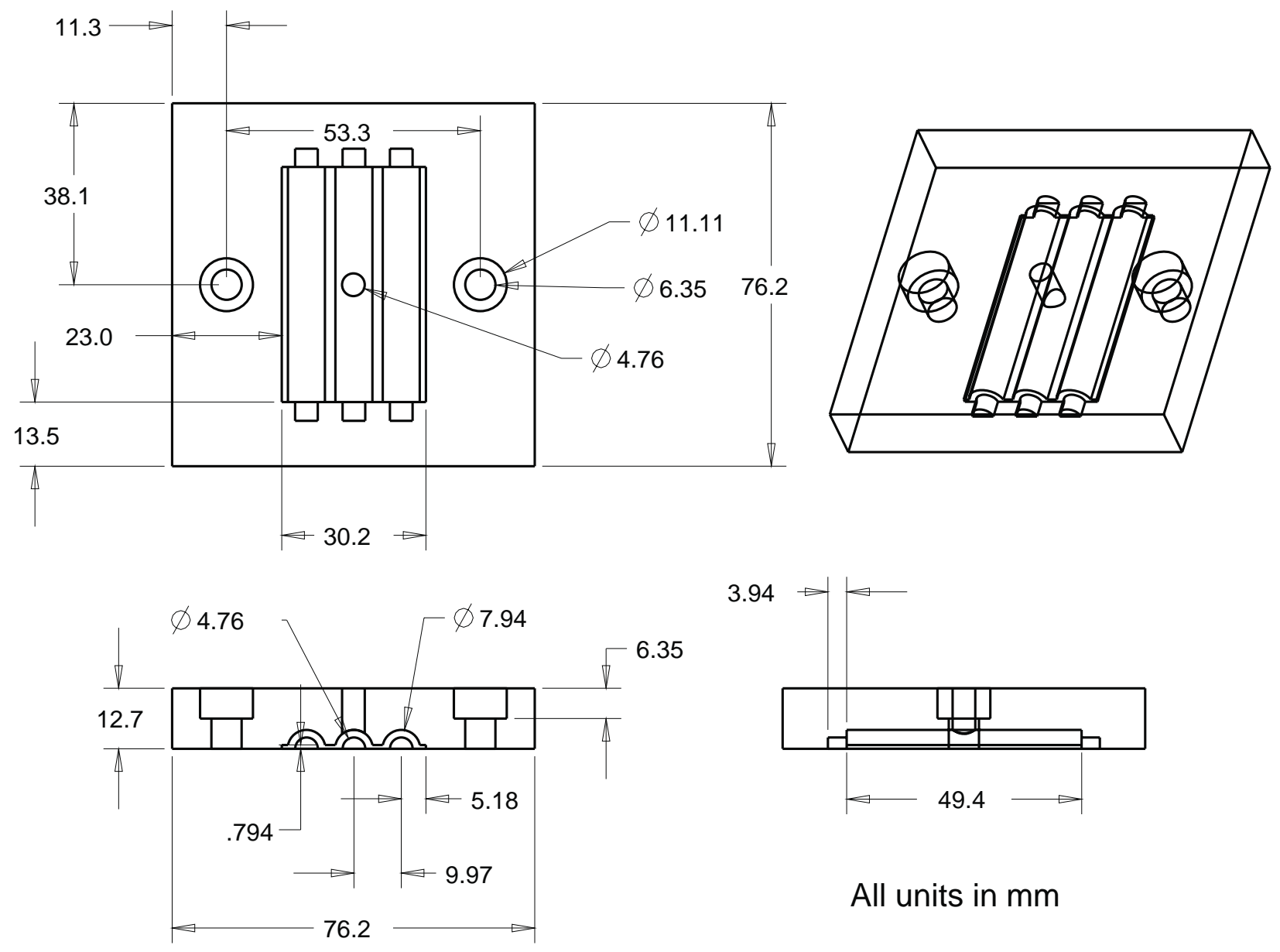

All units in $\mathrm{mm}$

191

192

Figure 7 Drawing of aluminum mold cavity for webbed-tube array

193 The completed webbed-tube arrays were then assembled (epoxied together) to form a $64.4 \mathrm{~mm} \times 54.3$ $194 \mathrm{~mm} \times 36.6 \mathrm{~mm}$ (or a $128 \mathrm{~cm}^{3}$ ) HX, as shown in Figure 8 and Figure 9. The inserts on the top and bottom 195 of the webbed-tube array were used to distribute the flow more evenly among the air channels. In total, 196 there were five "wavy" channels created by the 4 webbed-tube plates in this laboratory PHX prototype. 


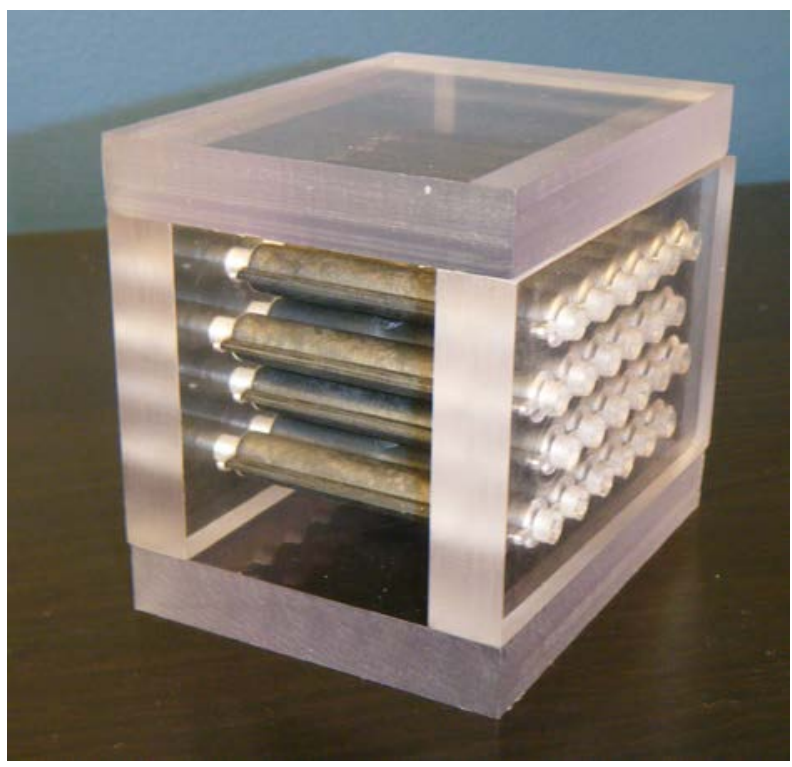

Figure 8 Picture of assembled webbed tube heat exchanger

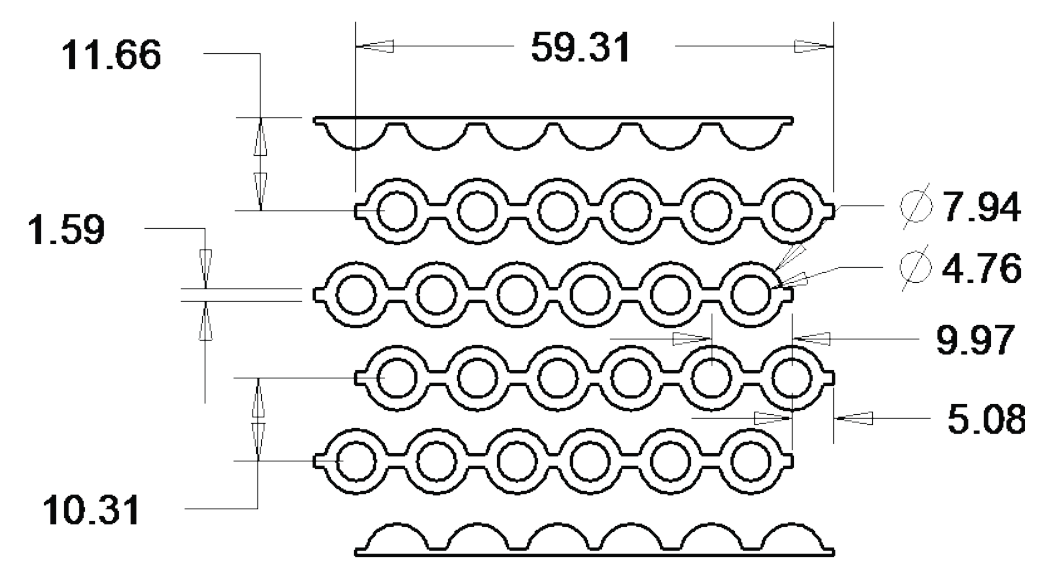

\section{All units in $\mathrm{mm}$}

\section{Thermal Anisotropy in the Webbed-Tube Array}

The results from the mold filling simulations in Moldflow also include a prediction of the local fiber orientation tensor, which identified significant anisotropy in the polymer wall of the injection molded prototype. An in-depth study of this process-induced anisotropy [14] showed that the fiber orientation tensor can be used, along with the Nielsen model [19], to calculate the local thermal conductivity tensor. The orientation average for a second-order thermal conductivity tensor, $\mathbf{\kappa}$, is defined as

$$
\langle\mathbf{\kappa}\rangle \equiv \oint \boldsymbol{\kappa}(\mathbf{p}) \psi(\mathbf{p}) d \mathbf{p}
$$

where $\mathrm{Z}$ is a probability distribution function for fiber orientation and $\mathbf{p}$ is the unit vector describing fiber orientation. If we consider $\boldsymbol{\kappa}$ to be transversely isotropic, the tensor must have the form 


$$
\kappa_{i j}(\mathbf{p})=A_{1} p_{i} p_{j}+A_{2} \delta_{i j}
$$

209 where $A_{1}$ and $A_{2}$ are scalar constants and $\mathrm{C}$ is the Dirac delta function. Taking the orientation

210 average yields

$$
\langle\kappa\rangle_{i j}=A_{1}\left\langle p_{i} p_{j}\right\rangle+A_{2}\left\langle\delta_{i j}\right\rangle
$$

211 which can be simplified to

$$
\langle\kappa\rangle_{i j}=A_{1} a_{i j}+A_{2} \delta_{i j}
$$

212 This result means that the orientation average of the second-order thermal conductivity tensor is

213 "completely determined by the second-order orientation tensor, and by the underlying

214 unidirectional property tensor" [23].

215 Let us, then, define an arbitrary transversely isotropic thermal conductivity tensor as

$$
\boldsymbol{\kappa}=\left[\begin{array}{ccc}
k_{x x} & 0 & 0 \\
0 & k_{y y} & 0 \\
0 & 0 & k_{z z}
\end{array}\right]
$$

216 with the x-axis as its axis of symmetry, so that

$$
p=(1,0,0)
$$

217 Following equation (2) we can say that

$$
\begin{aligned}
& k_{x x}=A_{1}(1)(1)+A_{2}(1) \\
& k_{y y}=A_{1}(0)(0)+A_{2}(1)
\end{aligned}
$$

218 Solving for $A_{1}$ and $A_{2}$ gives

$$
\begin{gathered}
A_{2}=k_{y y} \\
A_{1}=k_{x x}-k_{y y}
\end{gathered}
$$

219 Since $\boldsymbol{\kappa}$ is a transversely isotropic tensor with an x-axis of symmetry, $k_{x x}$ corresponds to the thermal 220 conductivity in the direction of fiber alignment, and $k_{y y}=k_{z z}$ corresponds to the thermal conductivity 221 in the direction transverse to the axis of fiber alignment. We can generalize equations (9) and (10) 222 as

$$
\begin{gathered}
A_{2}=k_{\perp} \\
A_{1}=k_{\|}-k_{\perp}
\end{gathered}
$$

223 Finally, equation (4) becomes 


$$
\langle\kappa\rangle_{i j}=\left(k_{\|}-k_{\perp}\right) a_{i j}+k_{\perp} \delta_{i j}
$$

Figure 10 shows the calculated components of the thermal conductivity tensor along a radial line with an angle of $70^{\circ}$ with respect to the horizontal axis of the WTHX orientation shown in Figure 9 . This radial locus was taken as a representative path through the tube wall, showing the range of thermal conductivities expected around the circumference of the tube. Using equation (13), with the Nielsenpredicted transverse and aligned conductivities [17], the thermal conductivity tensor can be readily calculated.

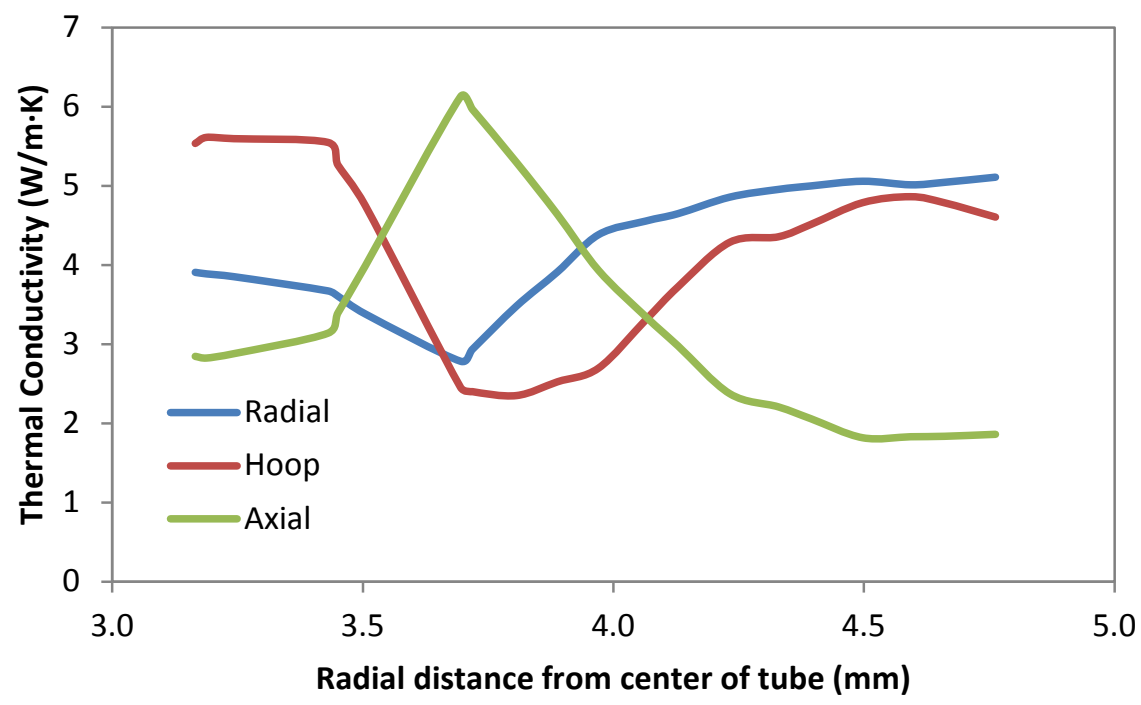

Figure 10 Thermal conductivity tensor components along the radius of the tube at an angle of $70^{\circ}$ with respect to the horizontal axis of the WTHX orientation shown in Figure 9

The thermal conductivity results shown in Figure 10 are quite illuminating. Generally, the fiber orientation tensor component and the resulting thermal conductivity in the thru-wall direction in an injection-molded component is very low. This occurs because the fibers tend to align with the streamlines of the melt flow. Therefore, one would expect the radial thermal conductivity in the present configuration to be much lower than in the hoop direction. However, it appears that the fluid forces, associated with the melt flow within the curved channel creating the wall of the circular tube, induce a complex fiber orientation pattern that provides a more limited range of thermal conductivity variation than might have been anticipated. Thus, as seen in Figure 10, the conductivity for all 3 principle directions varies between $2 \mathrm{~W} / \mathrm{m} \cdot \mathrm{K}$ and $6 \mathrm{~W} / \mathrm{m} \cdot \mathrm{K}$ and displays significantly less local anisotropy than was suggested by the Nielsen limits of $0.75 \mathrm{~W} / \mathrm{m} \cdot \mathrm{K}$ in the transverse direction and $9.7 \mathrm{~W} / \mathrm{m} \cdot \mathrm{K}$ in the fiberaligned direction. Moreover, it is seen that the thermal conductivity in the radial direction is remarkably similar to the hoop direction, for much of the wall thickness of the webbed-tube geometry selected for this laboratory prototype. These results suggest that the "effective" thermal conductivity in this webbed-tube heat exchanger plate, reflecting the dominance of the "radial" heat flow direction, along 
with local multi-axis heat flow, would be significantly higher than the lower bound thermal conductivity of $k_{\perp}=0.75 \mathrm{~W} / \mathrm{m} \cdot \mathrm{K}$.

\section{Analytical Modeling of a Webbed-Tube Heat Exchanger}

Currently, there are no correlations available to predict the expected heat transfer rate for air flow over a webbed-tube array in cross-flow. Therefore, we used Nusselt number correlations for the closest available geometries to the webbed-tube array, i.e. duct flow (ignoring the waviness of the channel wall) and tube-bundle flow (ignoring the presence of the "web" between the tubes) to bound the expected values. Only the Nusselt number expected for air flow is considered here, as the water flow inside the tubes of the webbed-tube array provides a heat transfer coefficient large enough to make the waterside thermal resistance negligible compared to the air side. As shown in Appendix A, we used duct flow and staggered tube bundle correlations from the literature to predict the Nusselt number as a function of Reynolds number, yielding the results shown in Figure 11. The Reynolds numbers in the laboratory WTHX study were no greater than 2300 due to equipment limitations, so only the laminar flow correlations were needed. In the case of the duct flow correlations (equations 24 - 34 in Appendix A), the flow length is short relative to the thermal or hydrodynamic entry length, and so the temperature and velocity profiles are simultaneously developing. It is to be noted that the Nu variation predicted by the staggered tube bundle correlation (equations 35 - 36 in Appendix A) has been "smoothed" to avoid several discontinuities, resulting from the use of different forms of the equation in different ranges of the Reynolds number.

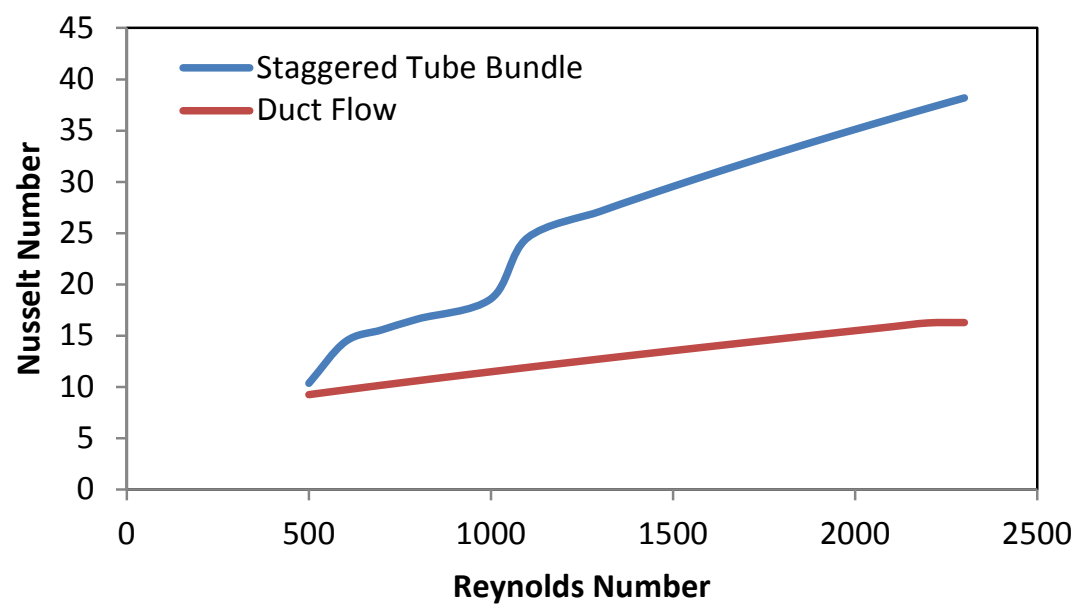

While the values of the two bounding Nusselt numbers correlations are close at a Reynolds number of 500 , the values quickly depart from each other as the Reynolds number increases towards the 1000 2300 Reynolds range of the empirical data. In the absence of a theoretical prediction and/or measured and correlated data for the "wavy" channels of a WTHX and recognizing the limitations of widely separated bounding relations, a detailed computational fluid dynamics simulation was used to provide more accurate values of the heat transfer coefficient in these webbed-tube channels. 


\section{Numerical simulation of webbed-tube heat exchanger}

ANSYS Icepak [24], which serves as a front-end tool to ANSYS Fluent, was used to simulate the thermofluid performance of the webbed-tube prototype heat exchanger. Using a 2D mesh-refined $(400,000$ elements) vertical slice in the center of the WTHX, a CFD simulation was performed for the thermo-fluid conditions of the cross flow test apparatus. The numerical simulation provided the flow and temperature distribution inside the webbed-tube heat exchanger, as well as the average heat transfer coefficient for the range of mass flow rates under study. Figure 12 shows an illustration of the air velocity streamlines, for an air mass flow rate of $4 \mathrm{~g} / \mathrm{s}$, inside the "wavy wall" air channels of the webbed-tube heat exchanger at the plane bisecting the WTHX midway through its depth (depth direction is into the page). The plot reveals the wavy shape of the streamlines, undulating to conform to the staggered arrangement of the tubes. However, it may be noted that the flow fails to penetrate the "trough" between the tubes, resulting in very low air velocities close to the web wall. Consequently, the heat transfer coefficient is also much lower across the webbing than around the circumference of the tube. Further study revealed that the webbing heat transfer coefficient was as much as an order-ofmagnitude lower than the crest of the tube [22].

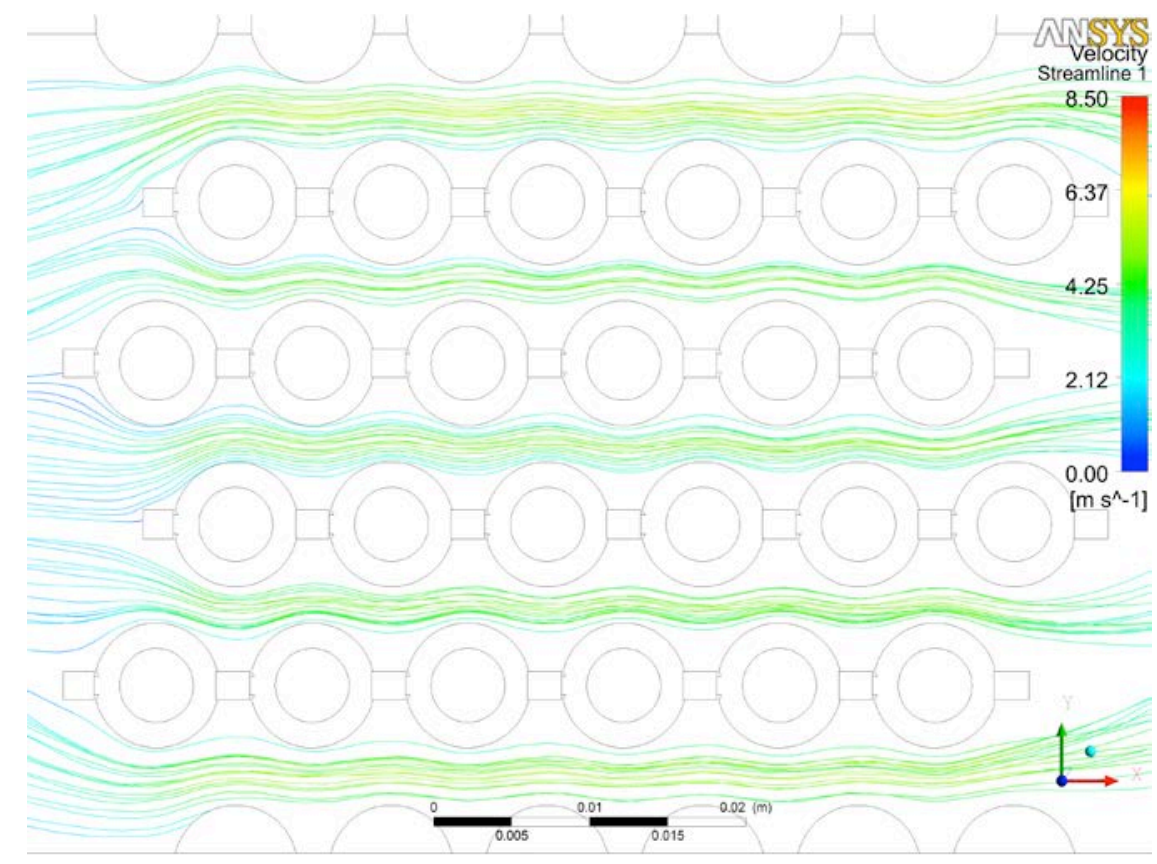

Figure 12 Cross-section of velocity streamlines at the WTHX center plane (mass flow $=4 \mathrm{~g} / \mathrm{s}$, inlet temperature $=116^{\circ} \mathrm{C}$ )

The results in Figure 12 also revealed that despite the inserts on the top and bottom of the heat exchanger, mimicking the role of additional webbed-tube arrays in a larger heat exchanger, there was still some bypass flow on the top and bottom air channels. As a result, the mean velocities are also higher on the top and bottom channels. It was determined from the numerical results that, in the laboratory WTHX, approximately $26 \%$ of the flow goes through each of the top and bottom channels, while only $16 \%$ of the flow passes through each of the three middle channels. 


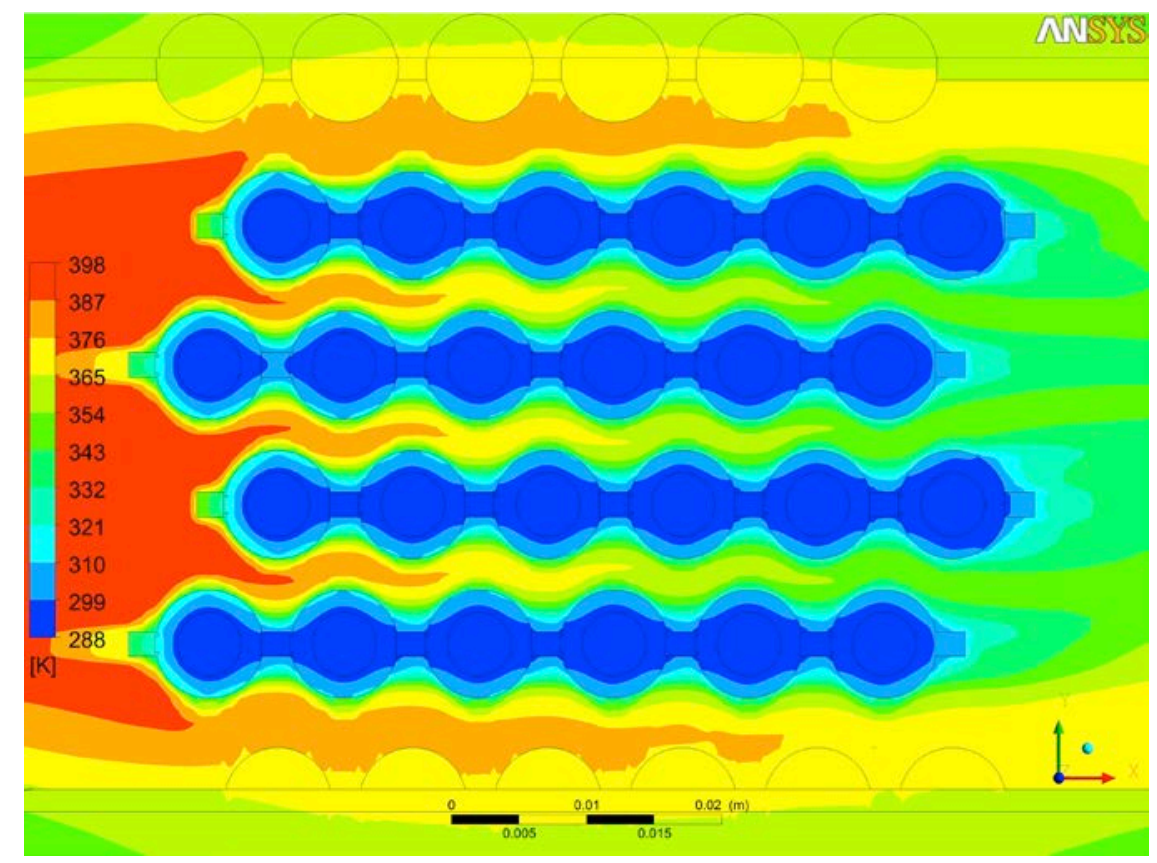

Figure 13 Cross section of temperature contours across WTHX center plane (mass flow $=4 \mathrm{~g} / \mathrm{s}$, inlet temperature $=116^{\circ} \mathrm{C}$ )

300 Examining Figure 13, it may be seen that the higher flow rates in the top and bottom "boundary" 301 channels, combined with the asymmetric (one side only) cooling in these channels, results in a 302 significant difference between the sensible cooling of the "boundary" channel flow and that of the flow in the central channels. Thus, for the conditions of Figure 13, while the central channel air has cooled from $120^{\circ} \mathrm{C}$ to $76^{\circ} \mathrm{C}$, the bottom and top channel air is $15^{\circ} \mathrm{C}$ warmer at $91^{\circ} \mathrm{C}$.

305 In this numerical study, the total heat transfer rate for the polymer heat exchanger was calculated using the specific inlet-to-outlet temperature difference and flow rate in each channel. The five resulting values of heat transfer are then added together to make up the total heat transfer rate. The heat transfer rates, calculated using the five temperature differences, were found to be within $2 \%$ of the actual heat transfer rates calculated by ANSYS-Icepak [22], integrating across all the surface area of the heat exchanger and using the heat flux at the surface of the tubes in the range of mass flow rates used in the experiment $(1.5-4.6 \mathrm{~g} / \mathrm{s})$. Thus, either approach can be used to calculate an overall heat transfer coefficient for specific operating conditions and that value can be compared to the values provided by the two sets of correlations discussed in the previous section, i.e. the duct flow correlation (equations

$31424-34$ in Appendix A) and the staggered tube correlation (equations 35-36 in Appendix A).

Figure 14 compares the heat transfer coefficients predicted by the two sets of correlations with the coefficients calculated in Icepak, showing a peak average value of $99 \mathrm{~W} / \mathrm{m}^{2} \cdot \mathrm{K}$ at a mass flow rate of 5 $\mathrm{g} / \mathrm{s}$, and suggesting that the wavy channel results are somewhat closer, though higher, than the prediction of the duct flow correlation. Figure 14 also reveals that the Icepak results are well bounded from below by the duct flow correlation and from above by the tube bundle correlation, with the exception of the heat transfer coefficient at a mass flow rate of $1 \mathrm{~g} / \mathrm{s}$. Interestingly, while the numerically-derived heat transfer coefficients are closer in value to the predictions based on duct flow, 
the slope of the curve seen in Figure 14, i.e. the power law variation with the mass flow rate at 0.675 , is closer to that of the tube bundle correlations at the higher flow rates. Moreover, at the upper flow rates of interest, there is more than a factor of 2 separating these two correlations. Since far more accurate values are desired, the numerical results are preferred for the analysis done in this study.

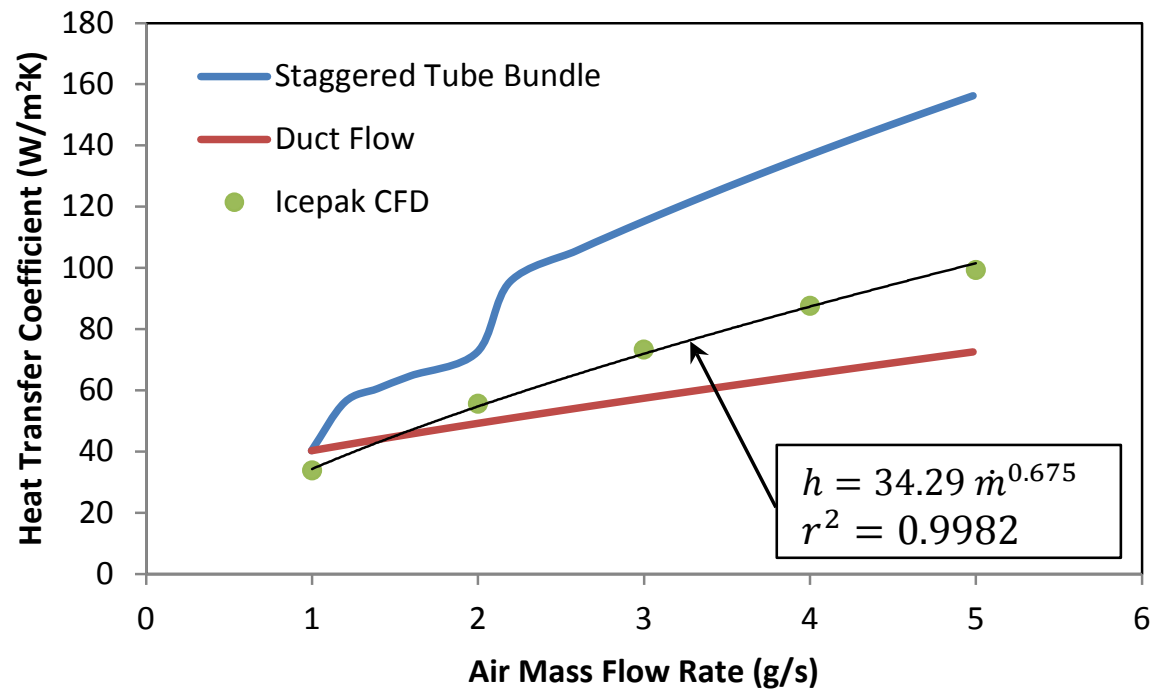

Figure 14 Heat transfer coefficient as a function of air mass flow rate

$$
h=34.29 \dot{m}^{0.675}
$$

\section{Experimental Methods}

The WTHX was tested with an air-to-water heat exchange apparatus, illustrated in Figure 15. Air was driven by a blower (Dayton Electric 4C006B) into a $5 \mathrm{~cm}$-diameter pipe that was $1.8 \mathrm{~m}$ long. Along the pipe, the air was heated by a resistance heater to temperatures of up to $120^{\circ} \mathrm{C}$. The air then flowed through the WTHX heat exchanger and through a vortex-shedding flow meter (Yokogawa YEWFLO FV$510 C$ with a range of 0-27 SCFM), with an accuracy of $1 \%$ of the flow meter reading. Afterwards, the air flowed through a secondary shell-and-tube heat exchanger to cool it down to room temperature. Water was fed to the heat exchanger at the building temperature and pressure. The water flow rate was measured with a vortex-shedding flow meter (Oval Eggs DELTA Pulse FLP04-L1NA). The measurement accuracies of the key quantities are summarized in Table 2. 


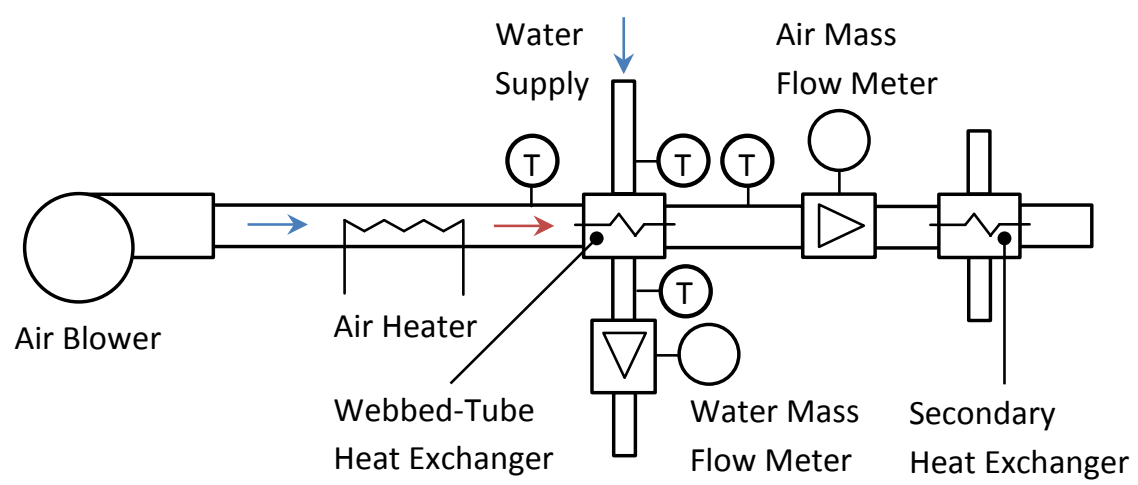

$\begin{array}{cc}\text { Measured Quantity } & \text { Accuracy } \\ \text { Water flow rate } & \pm 3 \% \text { of full scale } \\ \text { Air flow rate } & \pm 1 \% \text { of reading } \\ \text { Temperature } & \pm 0.5^{\circ} \mathrm{C}\end{array}$

348 Along with the two flow rates, air temperature is measured with type $T$ thermocouples placed at the 349 inlet and outlet of the heat exchangers, and surface temperature is measured at several locations in the 350 heat exchanger. Figure 16 illustrates the locations of the thermocouples with red dots. Ten 351 thermocouples were placed at the inlets and outlets of the channels. In addition, ten thermocouples 352 were embedded in the surface of a central webbed-tube array on both the tubes and the webbings 353 between the tubes. 


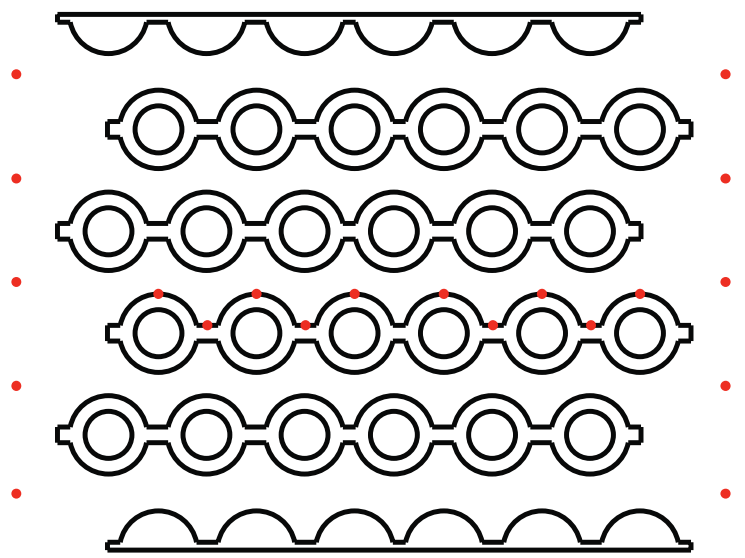

Figure 16 Thermocouple locations marked by red circles. Thermocouples are centered relative to the $\mathrm{HX}$ width (into the page)

The Reynolds number of the air flow was limited to the laminar flow regime $(<2300)$ due to equipment limitations. The water flow rate was large enough that the temperature change in the water was essentially negligible, and, therefore, the webbed-tube array walls could be modeled as constant temperature. The small water temperature change made an energy balance on the two fluid streams relatively inaccurate; the heat flow was measured to be $\pm 25 \%$ at the lowest gas flow rates and $\pm 5 \%$ at the highest gas flow rates.

\section{Analysis of Experimental Results}

The experimental data gathered in the course of this study can be analyzed and evaluated with the analytical and numerical tools presented in the previous sections and Appendix $A$. The empirical values obtained for the WTHX heat transfer rate, the overall thermal conductance of the heat exchanger, and the effective thermal conductivity of the polymer composite are discussed below.

Heat Transfer Rate: Figure 17 displays the experimental heat transfer rate as a function of mass flow rate and mean air-to-water inlet temperatures, peaking at a transfer rate of $140 \mathrm{~W}$ for a temperature difference of $98^{\circ} \mathrm{C}$ and a mass flow rate of $4.8 \mathrm{~g} / \mathrm{s}$. Not surprisingly, the data show that, as the air mass flow rate increases, the heat transfer rate increases, reflecting the dependence of the heat transfer coefficient on the flow rate, as shown earlier in Figure 14, and the higher exit temperature of the air. It is also seen that, as the mean temperature difference between the air and the water and, hence, the driving force for heat transfer, increases from $70^{\circ} \mathrm{C}$ to $98^{\circ} \mathrm{C}$, so does the heat transfer rate in an approximately proportional manner. 


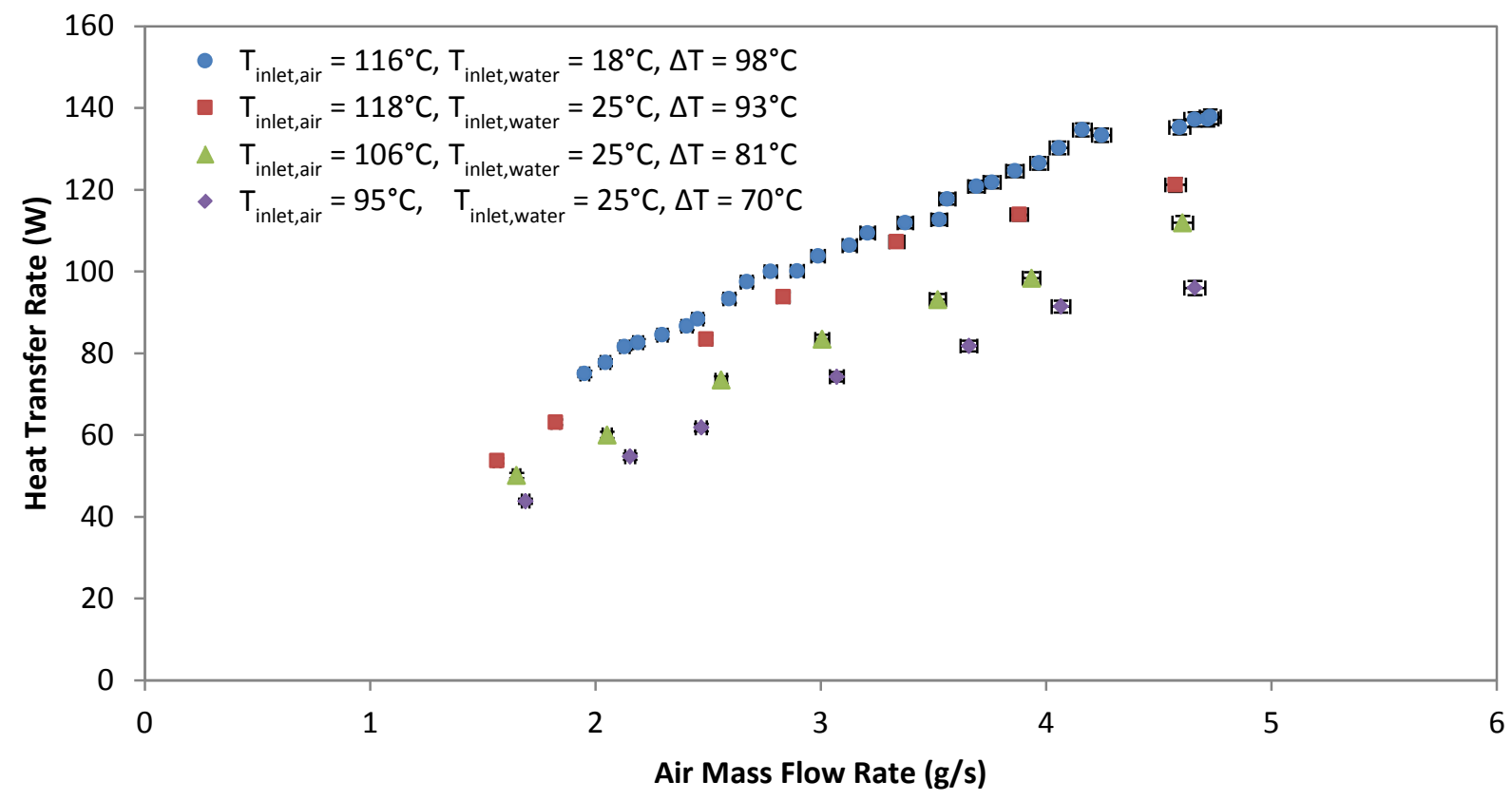

378 Thermal Conductance: The thermal conductance, UA, is a convenient metric for evaluating and

379 comparing heat exchangers. Returning to equation (16) in Appendix A, the overall thermal conductance 380 can be found by normalizing the heat transfer rate by the logarithmic mean temperature difference, which is defined in equation (21). The resulting values are plotted in Figure 18 and are seen to generate 382 a "collapsed" band of UA data that vary nearly-monotonically with the mass flow rate, from $0.7 \mathrm{~W} / \mathrm{K}$ at the lowest flow rate to $1.8 \mathrm{~W} / \mathrm{K}$ at the highest flow rate studied. Equation (15), relating the thermal conductance to the natural log of the air mass flow rate, correlates the entire dataset, with $r^{2}=0.99$ and with all but 5 of the 48 data points falling within $\pm 10 \%$ of this locus and, thus, serves to confirm the utility in representing the WTHX performance through the overall conductance, UA. It should be noted that equation (15) is a strictly parametric correlation, that may reflect direct, as well as indirect, dependencies of the UA on the mass flow rate and the authors are not suggesting a thermal-physical justification for the $\ln (\dot{m})$ dependence of the UA.

Nevertheless, it may be seen that the empirical UA results are as much as 1.65 times greater than the values that might have been anticipated for a "pure" polymer (thermal conductivity of $0.25 \mathrm{~W} / \mathrm{m} \cdot \mathrm{K}$ ), with no carbon fiber enhancement, for all but the lowest air mass flow rates. The empirical results, thus, point to the efficacy of a fiber-polymer composite in this application.

$$
\mathrm{UA}=0.94 \ln (\dot{m})+0.31
$$




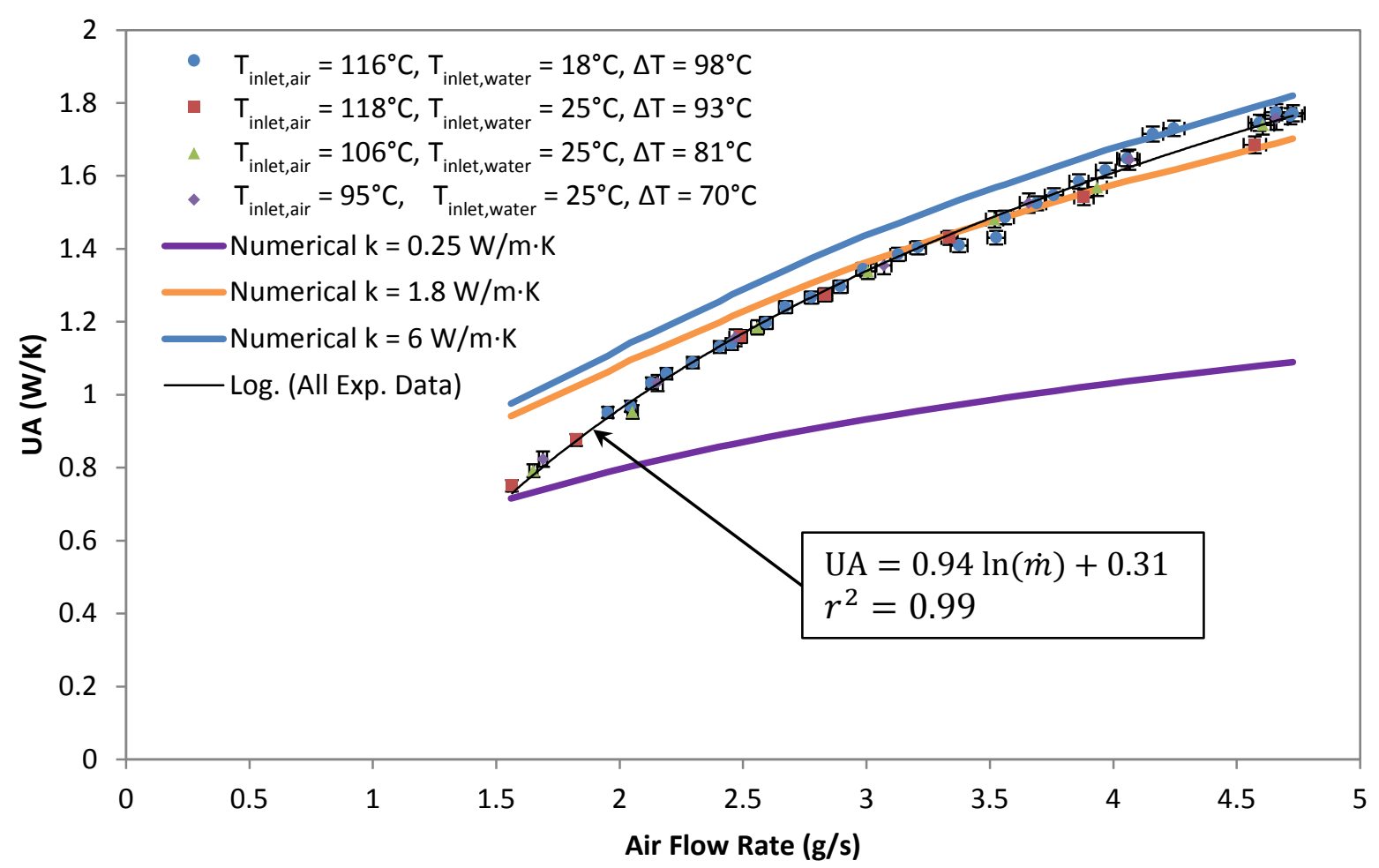

396 Effective Thermal Conductivity: The overall conductance, UA, of the experimental webbed-tube heat 397 exchanger includes contributions of convection in the wavy channel and conduction through the polymer wall, as seen in equations (17) - (20) in Appendix A. Using the numerically-derived heat transfer coefficients, calculated from equation (14), and the analytical modeling methods discussed in section 3 , UA values can be calculated with various isotropic thermal conductivities for the heat exchanger and compared to the empirical UA values. Assuming that any discrepancy between the modeled and empirical UA values, at a given mass flow rate, is due to the uncertainty in the effective thermal conductivity of the polymer composite wall, it is possible to "inversely" determine that thermal conductivity by finding the $\mathrm{k}$ value which yields the least squared sum of the discrepancies across the entire dataset. Figure 19 shows that a distinct, though shallow, minimum-in the squared sum of the discrepancy-was found in the present data set, yielding an effective polymer composite thermal

407 conductivity of $1.8 \mathrm{~W} / \mathrm{m} \cdot \mathrm{K}$. 


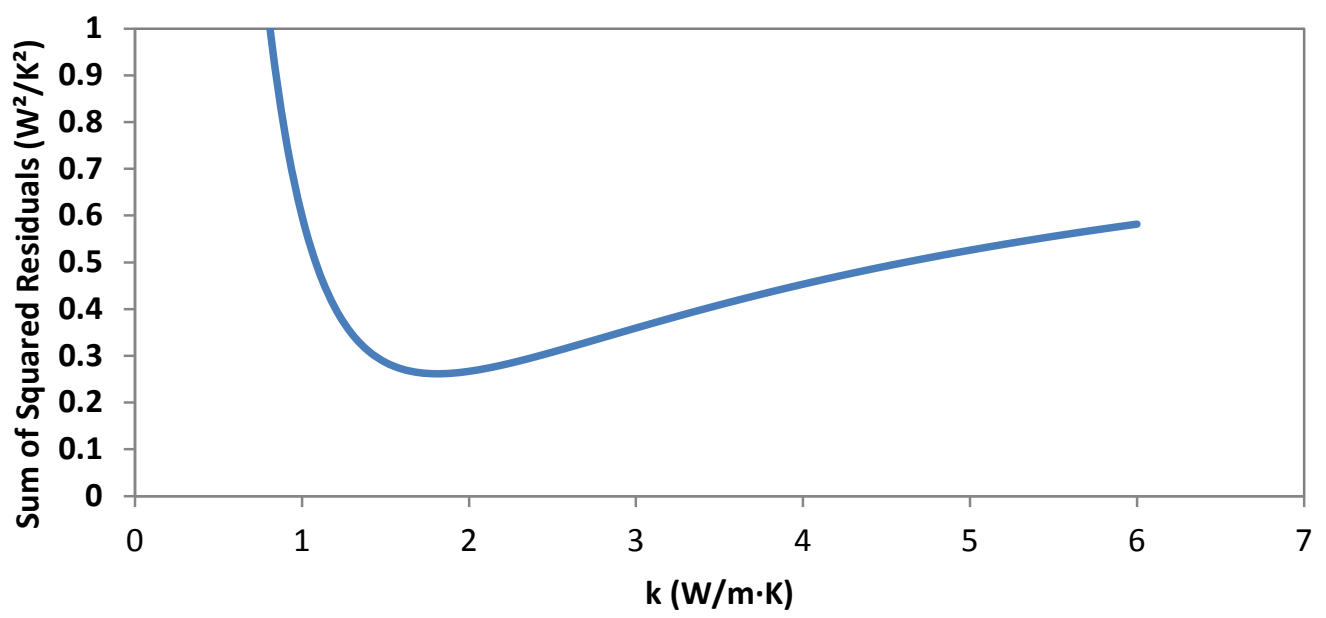

408

409

410 The "inversely" determined effective thermal conductivity of $1.8 \mathrm{~W} / \mathrm{m} \cdot \mathrm{K}$ appears to fit well with the core 411 part of the experimental data and provide agreement to within approximately $\pm 10 \%$ for flow rates

412 ranging from $2 \mathrm{~g} / \mathrm{s}$ to $4.7 \mathrm{~g} / \mathrm{s}$. It must, however, be noted that at the lower flow rates-and,

Figure 19 Sum of squared residuals as a function of thermal conductivity consequently, lower heat transfer coefficients-the UA can be expected to be less sensitive to the conductive resistance and more sensitive to the convective resistance and, thus, result in lower accuracy of any "extracted" value of $k$. Nevertheless, this result suggests that the effective thermal conductivity of the polymer composite wall may vary from lower to higher values as the air flow rate increases. In the present work, flow rates below $3.2 \mathrm{~g} / \mathrm{s}$ imply a thermal conductivity less than the nominal value of 1.8 $\mathrm{W} / \mathrm{m} \cdot \mathrm{K}$ and greater than the nominal value at flow rates above $3.2 \mathrm{~g} / \mathrm{s}$. Such a variation in the effective thermal conductivity has also been observed in previous work with injection molded polymer composite heat exchangers [11].

The apparent variations in the effective thermal conductivity may reflect the changes in the heat flow pattern and temperature dependent thermal conductivity within the anisotropic polymer walls. However, due to the relative insensitivity of the predicted UA values at the low mass flow rates and growing UA insensitivity, across the full parametric range, as the thermal conductivity increases precise quantification of this effect is beyond the scope of the present effort.

\section{Summary}

A polymer composite "webbed-tube" heat exchanger (WTHX) was developed for gas-liquid heat exchange. The WTHX design was informed by the thermal properties of the polymer composite and by the desire to harness the anisotropy in thermal conductivity that occurs in injection molded polymer composites. A laboratory prototype WTHX was fabricated and tested on an air-water heat exchange apparatus. The WTHX was constructed by assembling four webbed-tube arrays that were injection molded from Nylon 12 filled with pitch-based carbon fibers. The prototype was $128 \mathrm{~cm}^{3}$, and for the specific geometry constructed, the maximum heat transfer performance of $1.1 \mathrm{~W} / \mathrm{cm}^{3}$ was obtained with an air mass flow rate of $4.8 \mathrm{~g} / \mathrm{s}$ and a log-mean temperature difference of $78 \mathrm{~K}$. At this operating 
condition, the UA for the heat exchanger reached a value of $1.8 \mathrm{~W} / \mathrm{K}$ and the volume-specific heat transfer coefficient was found to equal $14 \mathrm{~kW} / \mathrm{m}^{3} \cdot \mathrm{K}$. The observed performance was approximately 1.65 times higher than could be expected from a heat exchanger using unenhanced polymer walls.

The carbon-fiber orientation in the injection molded composite was studied with computational simulations and coupled with the Nielsen model to analyze thermal conductivity anisotropy within the molded WTHX. In this study, the "effective" thermal conductivity of the Nylon 12 polymer composite tube wall was "inversely" calculated by determining the discrepancy between empirical and numerical data as a function of thermal conductivity and flow rate. The effective thermal conductivity that best represents the dataset was found to equal approximately $1.8 \mathrm{~W} / \mathrm{m} \cdot \mathrm{K}$. It was observed that effective thermal conductivity increased with air flow rate, which may reflect changes in heat flow pattern within the anisotropic polymer walls.

\section{Acknowledgements}

This research was performed as part of the Energy Education and Research Collaboration (EERC) between the University of Maryland and the Petroleum Institute in the UAE. The authors would like to thank the Abu Dhabi National Oil Company (ADNOC) and its international partners for their generous financial support. The authors would also like to gratefully acknowledge support from the United States National Science Foundation for completion of this study.

\section{References}

[1] R. E. Githens, W. R. Minor, and V. J. Tomsic, "Flexible-tube heat exchangers," Chemical Engineering Progress, vol. 61, pp. 55-62, 1965.

[2] G. K. Hart, C. o. Lee, and S. R. Latour, "Development of Plastic Heat Exchangers for Ocean Thermal Energy Conversion," DSS Engineers, Inc., 7483 N.W. Fourth Street, Ft. Lauderdale, Florida 33317 ORO-5165-1, January 1979.

[3] D. Miller, R. E. Holtz, R. N. Koopman, T. J. Marciniak, and D. R. MacFarlane, "Plastic heat exchangers: a state-of-the-art review," Argonne National Lab., IL (USA) ANL-79-12, July 1979.

[4] J. G. Cevallos, A. E. Bergles, A. Bar-Cohen, P. Rodgers, and S. K. Gupta, "Polymer Heat Exchangers--History, Opportunities, and Challenges," Heat Transfer Engineering, vol. 33, pp. 1075-1093, 2012.

[5] J. E. Hesselgreaves, Compact Heat Exchangers: Selection, Design and Operation: Elsevier Science, 2001.

[6] N. DuPont, Flue gas coolers with AlWaFlon ${ }^{\circledR}$ pressure hoses based on DuPont Teflon ${ }^{\circledR}$ PTFE maximize power plant efficiency: DuPont Fluorosolutions, 2009.

[7] S. J. Pugh, G. F. Hewitt, and H. Müller-Steinhagen, "Fouling During the Use of Seawater as Coolant-the Development of a User Guide," Heat Transfer Engineering, vol. 26, pp. 35-43, 2005/01/01 2005.

[8] L. Zaheed and R. J. J. Jachuck, "Review of polymer compact heat exchangers, with special emphasis on a polymer film unit," Applied Thermal Engineering, vol. 24, pp. 2323--2358, 2004.

[9] C. T'Joen, Y. Park, Q. Wang, A. Sommers, X. Han, and A. Jacobi, "A review on polymer heat exchangers for HVACR applications," International Journal of Refrigeration, vol. 32, pp. 763-779, 2009. 
[10] C. Zweben, "Emerging High-Volume Applications for Advanced Thermally Conductive Materials," Long Beach, California, 2004.

[11] F. Robinson, J. G. Cevallos, A. Bar-Cohen, H. Bruck, and Asme, "Modeling and validation of a prototype thermally-enhanced polymer heat exchanger," Proceedings of the Asme International Mechanical Engineering Congress and Exposition, 2011, Vol 1, pp. 597-606, 20122012.

[12] J. Cevallos, S. K. Gupta, and A. Bar-Cohen, "Incorporating Moldability Considerations During the Design of Polymer Heat Exchangers," Journal of Mechanical Design, vol. 133, p. 9, Aug 2011.

[13] P. Luckow, A. Bar-Cohen, P. Rodgers, and J. Cevallos, "Energy Efficient Polymers for Gas-Liquid Heat Exchangers," Journal of Energy Resources Technology, vol. 132, p. 021001, 2010.

[14] A. Bar-Cohen, P. Luckow, J. G. Cevallos, and S. K. Gupta, "Thermal Anisotropy in Injection Molded Polymer Composite Fins," presented at the International Heat Transfer Conference 14 Washington, DC, 2010.

[15] M. M. P. Data. (May 20). Cytec Thornel ${ }^{\circledR}$ P-100 2K Carbon Fiber, Pitch Precursor Available: http://www.matweb.com/search/DataSheet.aspx?MatGUID=dd21d18e267044a79df3e8d09de9 a420

[16] M. M. P. Data. (May 20). Overview of materials for Nylon 12. Available: http://www.matweb.com/search/DataSheet.aspx?MatGUID=0e37a459c4eb452faa9d92659f9a0 $\underline{\mathrm{CCC}}$

[17] PolyOne. (July 22). Therma-Tech NJ-600 TC. Available: http://catalog.ides.com/pdfdatasheet.aspx?l=55275\&E=85972

[18] ASTM Standard C177, "Standard Test Method for Steady-State Heat Flux Measurements and Thermal Transmission Properties by Means of the Guarded-Hot-Plate Apparatus," ed: ASTM International, West Conshohocken, PA, 2004.

[19] L. E. Nielsen, "The Thermal and Electrical Conductivity of Two-Phase Systems," Industrial \& Engineering Chemistry Fundamentals, vol. 13, pp. 17-20, 1974/02/01 1974.

[20] A. M. Lab. (May 20). Equipment Gallery. Available: http://www.aml.umd.edu/equipment/index.html

[21] A. M. Insight. (September 7). Available: http://usa.autodesk.com/adsk/servlet/index?sitelD=123112\&id=13195432

[22] J. G. Cevallos, "Thermal and manufacturing design of polymer composite heat exchangers," Doctor of Philosophy, College Park, MD, University of Maryland, 2014.

[23] S. G. Advani and C. L. Tucker III, "The Use of Tensors to Describe and Predict Fiber Orientation in Short Fiber Composites," Journal of Rheology, vol. 31, pp. 751-784, 1987.

[24] ANSYS Inc., "ANSYS Icepak 12.1," 2009.

[25] R. K. Shah and M. S. Bhatti, "Laminar convective heat transfer in ducts," in Handbook of SinglePhase Convective Heat Transfer S. Kakac, R. K. Shah, and W. Aung, Eds., ed New York: Wiley, 1987.

[26] R. K. Shah and D. P. Sekulic, Fundamentals of heat exchanger design. Hoboken, NJ: John Wiley \& Sons, 2003.

[27] B. S. Petukhov and V. N. Popov, "Theoretical calculation of heat exchange in turbulent flow in tubes of an incompressible fluid with variable physical properties " High Temp., vol. 1, pp. 69-83, 1963.

[28] M. S. Bhatti and R. K. Shah, "Turbulent and transition convective heat transfer in ducts," in Handbook of Single-Phase Convective Heat Transfer, S. Kakac, R. K. Shah, and W. Aung, Eds., ed New York: Wiley, 1987.

[29] R. K. Shah and A. L. London, "Laminar Flow Forced Convection in Ducts," in Supplement 1 to Advances in Heat Transfer, ed New York: Academic Press, 1978.

[30] P. Wibulswas, Laminar Flow Heat Transfer in Non-circular Ducts: University of London, 1966. 
[31] S. Kakaç, R. K. Shah, and W. Aung, Handbook of single-phase convective heat transfer: Wiley, 1987.

[32] G. Nellis and S. Klein, Heat Transfer: Cambridge University Press, 2009.

A. A. Zukauskas, "Convective heat transfer in crossflow," in Handbook of Single-Phase Convective Heat Transfer, S. Kakaç, R. K. Shah, and W. Aung, Eds., ed New York: John Wiley \& Sons, 1987. 


\section{Analytical Modeling of Webbed-Tube Heat Exchanger}

533 The heat transfer for any heat exchanger can be written as

$$
q=U A \Delta T_{l m}
$$

534 where $U A$ is the overall thermal conductance, and $\Delta T_{l m}$ is the log-mean temperature difference. The 535 overall thermal conductance is written as the inverse of the overall thermal resistance as

$$
U A=\frac{1}{R_{\text {total }}}
$$

536 For this heat exchanger, there are three thermal resistances that make up the overall thermal resistance

$$
R_{\text {total }}=R_{\text {conv }, 1}+R_{\text {wall }}+R_{\text {conv }, 2}
$$

537 where $R_{c o n v, 1}$ and $R_{c o n v, 2}$ are the convective thermal resistance for the air-side and the water side,

538 respectively. $R_{\text {wall }}$ is the conductive thermal resistance. For the webbed-tube heat exchanger, $R_{\text {conv }, 1}$ is 539 written as

$$
R_{\text {conv }, 1}=\frac{1}{\eta_{o} h A}
$$

540 where $\eta_{o}$ is the surface efficiency based on the fin efficiency, $h$ is the heat transfer coefficient and $A$ is 541 the surface area. The wall thermal resistance $R_{\text {wall }}$ is written as

$$
R_{\text {wall }}=\frac{\ln \left(r_{2} / r_{1}\right)}{2 \pi k L}
$$

542 where $r_{2}$ is the tube outer radius, $r_{1}$ is the tube inner radius, $k$ is the thermal conductivity, and $L$ is the 543 tube length.

544 The log-mean temperature difference is defined as

$$
\Delta T_{l m}=\frac{\Delta T_{1}-\Delta T_{2}}{\ln \left(\Delta T_{1} / \Delta T_{2}\right)}
$$

545 where for a counter-flow heat exchanger $\Delta T_{1}$ and $\Delta T_{2}$ are defined as

$$
\begin{aligned}
& \Delta T_{1}=T_{h, i}-T_{c, o} \\
& \Delta T_{2}=T_{h, o}-T_{c, i}
\end{aligned}
$$


where the subscripts $h, \mathrm{c}$, i, and o stand for hot fluid, cold fluid, inlet, and outlet, respectively.

547 For a cross flow heat exchanger a correction factor $\mathrm{F}$ can be applied to the counter-flow $\Delta T_{l m}$. However, 548 when the change in temperature in one of the fluids (water) is negligible, as is the case here, the

549 correction factor is 1.

550 Finally, an appropriate correlation must be selected for calculating the Nusselt number and the heat 551 transfer coefficient. For the webbed-tube heat exchanger, it was not immediately clear which

552 correlation can be used for the fluid outside of the tubes. In this study, correlations for flow in 553 rectangular ducts were considered using a hydraulic diameter $\left(D_{h}\right)$ based on the flow cross-sectional

554 area and the wetted perimeter. If the heat exchanger is arranged in a cross flow configuration, the flow 555 outside of the tubes looks very similar to a tube bundles, except that the webbing connecting the tubes 556 prevents mixing between rows of tubes. Nevertheless, tube bundle correlations were also considered in 557 this study.

\section{Flow in rectangular ducts}

559 Fully Developed Flows

560 For a laminar, hydrodynamically and thermally fully developed flow in a rectangular duct exposed to a 561 uniform heat flux and uniform wall temperature, the friction factor and Nusselt number data was

562 provided by Shah and Bhatti [25] as shown in [26].

563 The product of the fully developed friction factor and the Reynolds number is a function of the aspect 564 ratio $\alpha$ :

$$
f_{f d}=\frac{24}{R e_{D_{h}}}\left(1-1.3553 \alpha+1.9467 \alpha^{2}-1.7012 \alpha^{3}+0.9564 \alpha^{4}-0.2537 \alpha^{5}\right)
$$

565 The Nusselt number correlation for constant temperature is

$$
N u_{f d, T}=7.541\left(1-2.610 \alpha+4.970 \alpha^{2}-5.119 \alpha^{3}+2.702 \alpha^{4}-0.548 \alpha^{5}\right)
$$

566 For turbulent flow, the Petukhov and Popov [27]correlation, shown below, was chosen because it has 567 the best accuracy $( \pm 5 \%)$ of the correlations presented by Shah and Sekulic [26].

$$
\begin{gathered}
N u=\frac{(f / 2) R e \cdot \operatorname{Pr}}{C+12.7(f / 2)^{1 / 2}\left(\operatorname{Pr}^{2 / 3}-1\right)} \\
4000 \leq \operatorname{Re} \leq 5 \times 10^{6} \\
0.5 \leq \operatorname{Pr} \leq 10^{6} \\
C=1.07+\frac{900}{\operatorname{Re}}-\frac{0.63}{1+10 \operatorname{Pr}}
\end{gathered}
$$


568 The friction factor for turbulent flow in a smooth duct can be obtained with an accuracy of $\pm 2 \%$ by using 569 a correlation provided by Bhatti and Shah [28] as presented in [26].

$$
f=0.00128+0.1143 R e^{-0.311}
$$

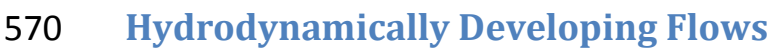

571 Friction factors in the entrance region are higher than in the fully developed region. As shown by Shah

572 and Sekulic [26], the hydrodynamic entrance length in a circular tube is given by

$$
\frac{L_{h y}}{D_{h}}= \begin{cases}0.056 R e & \text { for laminar flow }(\operatorname{Re} \leq 2100) \\ 1.359 R e^{1 / 4} & \text { for turbulent flow }\left(\operatorname{Re}>10^{4}\right)\end{cases}
$$

573 In laminar flow, the apparent friction factor in the entrance region in circular and some noncircular

574 ducts is calculated with the following [29]:

$$
f_{a p p} \cdot R e=3.44\left(x^{+}\right)^{-0.5}+\frac{K(\infty) /\left(4 x^{+}\right)+f R e-3.44\left(x^{+}\right)^{-0.5}}{1+C^{\prime}\left(x^{+}\right)^{-0.2}}
$$

575 where

$$
x^{+}=\frac{x}{D_{h} R e}
$$

576 and values for $K(\infty)$ and $C^{\prime}$ can be obtained from [29].

577 While the turbulent friction factors in the entrance region are higher than those in the fully developed

578 flow, the entrance length is very short and does not influence the pressure drop significantly, compared

579 to other factors. Therefore, it is generally neglected when evaluating the pressure drop [26].

580 Thermally developing flows

581 The mean Nusselt number for developed velocity profiles and developing temperature profiles in

582 laminar flow were correlated by Shah and London [29] as

$$
\begin{aligned}
& N u_{m, T}=0.641(f \cdot R e)^{1 / 3}\left(x^{*}\right)^{-1 / 3} \\
& N u_{m, H}=0.775(f \cdot R e)^{1 / 3}\left(x^{*}\right)^{-1 / 3}
\end{aligned}
$$

583 where $f$ is the friction factor for fully developed flow and $x^{*}=x /\left(D_{h} \cdot \operatorname{Re} \cdot \operatorname{Pr}\right)$

584 Bhatti and Shah [28] provided correlations for Nusselt numbers in the thermal entrance region. For

$585 \mathrm{Pr}=0.7$ the following correlation gives Nusselt number values within $\pm 12 \%$ of experimental values.

$$
\frac{N u_{m}}{N u_{\infty}}=1+\frac{C_{6}}{x / D_{h}}
$$




$$
x / D_{h}>3,3500<\operatorname{Re}<10^{5} \text {, and } 0.7<\operatorname{Pr}<75
$$

586 with

$$
C_{6}=\frac{\left(x / D_{h}\right)^{0.1}}{\operatorname{Pr}^{1 / 6}}\left(0.68+\frac{3000}{R e^{0.81}}\right)
$$

587 Simultaneously Developing Flow

588 In laminar flow, heat transfer in the thermal entrance region is higher for a developing velocity profile

589 than for a fully developed profile [26]. The values of the Nusselt number for simultaneously developing 590 flow in a rectangular duct with constant wall temperature and $\mathrm{Pr}=0.72$ was provided by Wibulswas

591 [30]. The values were adjusted for other Prandtl numbers as shown by Kakaç et. al. [31]. The following 592 approach was taken from Nellis and Klein [32].

593 A dimensionless length appropriate for a thermally developing flow is $L^{*}$, sometimes referred as the 594 inverse of the Graetz number:

$$
L^{*}=\frac{1}{G z}=\frac{L}{D_{h} R e_{D_{h}} P r}
$$

595 For a constant wall temperature:

$$
\begin{gathered}
a_{T}=0.0357122+0.460756236 \alpha-0.214865737 \alpha^{2} \\
b_{T}=\left\{\begin{array}{cl}
0.940362+\alpha(0.739606-0.940362) / 0.167, & \alpha<0.167 \\
0.801105912-0.419264242 \alpha+0.293641181 \alpha^{2}, & \alpha \geq 0.167
\end{array}\right. \\
A=a_{T} e^{-b_{T} \ln L^{*}} \\
B=\left\{\begin{array}{cl}
0.6847+0.3153 e^{-1.26544559(\ln P r-\ln 0.72)}, & \operatorname{Pr}>0.72 \\
1.68-0.68 e^{0.32(\ln P r-\ln 0.72)}, & \operatorname{Pr} \leq 0.72 \\
\overline{N u}_{T} \approx N u_{f d, T}+A \cdot B &
\end{array}\right.
\end{gathered}
$$

596 Heat transfer in tube bundles

597 In this study, we are only interested in staggered arrays of webbed tubes. Therefore, only Nusselt 598 number correlations for a staggered array of tubes by Zukauskas [33], shown in [34], were used.

599 The average Nusselt number for a staggered tube bundle in cross flow is: 


$$
\overline{N u}_{b}=\left\{\begin{array}{c}
1.04 c_{n} \operatorname{Re}_{b}^{0.4} \operatorname{Pr}_{b}^{0.36}\left(\frac{P r_{b}}{P r_{w}}\right)^{0.25} \text { for } R e_{b}=1-500 \\
0.71 c_{n} \operatorname{Re}_{b}^{0.5} \operatorname{Pr}_{b}^{0.36}\left(\frac{P r_{b}}{P r_{w}}\right)^{0.25} \text { for } R e_{b}=500-10^{3} \\
0.35 c_{n} R e_{b}^{0.6} \operatorname{Pr}_{b}^{0.36}\left(\frac{P r_{b}}{P r_{w}}\right)^{0.25}\left(\frac{X_{t}}{X_{l}}\right)^{0.2} \text { for } R e_{b}=10^{3}-2 \times 10^{5} \\
0.35 c_{n} \operatorname{Re}_{b}^{0.8} \operatorname{Pr}_{b}^{0.4}\left(\frac{P r_{b}}{P r_{w}}\right)^{0.25}\left(\frac{X_{t}}{X_{l}}\right)^{0.2} \text { for } R e_{b}=2 \times 10^{5}-2 \times 10^{6}
\end{array}\right.
$$

600 where $X_{1}$ is the longitudinal spacing of consecutive rows, and $X_{t}$ is the transversal spacing of two 601 consecutive tubes, while $c_{n}$ is a correction factor for the number of tube rows [34]. The Reynolds 602 number is calculated using the maximum average velocity $\left(u_{\max }\right.$, velocity occurring at minimum flow 603 cross section) and the tube outer diameter(D):

$$
R e_{b}=\frac{\rho u_{\max } D}{\mu}
$$

604 The Zukauskas correlation is said to have an uncertainty within $\pm 15 \%$ [34]. 